\title{
Study and Application of HSK Exam Simulation Media
}

\author{
Darmanto $^{1}$, Yulius Hari ${ }^{2}$, Budi Hermawan ${ }^{3}$, Endang Sulistyowati ${ }^{4}$ \\ \{darmanto2@ hotmail.com ${ }^{1}$, yulius.hari.s@gmail.com ${ }^{2}$ \} \\ Universitas Widya Kartika, Indonesia ${ }^{1,2,3}$ \\ Universitas Kartini, Indonesia ${ }^{4}$
}

\begin{abstract}
Along with the economic development in the Industrial Revolution 4.0 era, the ability to speak Mandarin is a necessity both in the world of business and education. In the Chinese language field, obtaining HSK Certification as a stimulant for students to improve their academic qualifications. Similarly, it is not uncommon for workers or prospective employees to seek certification to improve their professionalism. Various high school or university with mandarin language competency requires students to pass the HSK certification exam at a certain level. The emergence of a combination of innovative products in the field of Electronics and Information Technology has been the driving force behind the development of an application of the Hanyu Shuiping Kaoshi (HSK) as a supporting medium to support the preparation of the HSK exam. The local application created is expected to complement the media available at the Google Play digital store. Specifically, this media was tested as an exam simulation application for Nurul Jadid Probolinggo high school students and Mandarin study program students at Widya Kartika University, which required students and students to pass HSK levels 4 and 5. Based on student or student responses, this application was quite significant as a supporting medium. paper-based or online HSK exam preparation.
\end{abstract}

Keywords: HSK, Foreign Language Learning, Learning Media

\section{Introduction}

Mandarin is one of the official languages set by the United Nations (UN) organization. Nowadays, Mandarin has become very important and has become the second international language after English. Along with the economic development in the Industrial Revolution 4.0 era, the ability to speak Mandarin became a necessity both in the world of business and education. Mandarin is not only useful in business matters, but many other things too. The Mandarin competency test, also known as the HSK which stands for Hanyu Shuiping Kaoshi, was initiated by the Chinese Hanban, to provide information about one's Mandarin competence. This test is the result of collaboration of experts from China and from outside China by involving experts in the discipline of Mandarin Language Teaching, Linguistics, Psychology and Education [1].

In learning Mandarin, get HSK Certification as a stimulant for students, students or employees to improve their competency qualifications. According to the main needs in the Business World and the Industrial World, someone with Mandarin language skills has the competitiveness to seize available employment opportunities. Getting to know someone's abilities and skills in Mandarin language can be proven among them by the HSK certification obtained from the results of passing the HSK test. This HSK certification has an equivalent function to the TOEFL \& IELTS test for English. This certificate shows valid recognition of 
one's Mandarin language skills [1]. However, to obtain an HSK certificate for non-native speakers, it must pass an HSK test organized by the Confucius Institute Headquarter, or abbreviated as Hanban. Hanban has collaborated with various educational institutions around the world in conducting HSK test exams, including in Indonesia [2]. Indonesia is one of 120 countries that have participated as HSK providers since 2005. There are two types of HSK examinations, namely computer-based tests and paper-based tests. However, the standard and method of assessment are the same, only different in providing answer input on the test form. The test material given in HSK is the use of Mandarin in daily life, in education and professionalism. HSK consists of six levels, namely HSK (level) I), HSK (level II), HSK (level III), HSK (level IV), HSK (level V), and HSK (level VI) [3].

Achievement competency Test participants who are able to pass HSK (Level I), which can understand and use very simple Chinese words and phrases, meet basic needs for communication and have the ability to continue their Mandarin studies. Achievement Competencies Test participants who are able to pass HSK (Level II) have a very good understanding of basic Mandarin and will communicate in simple and routine tasks that require the exchange of simple and direct information about general and routine problems. Achievement Competencies Test participants who are able to pass HSK (Level III) will communicate in Mandarin at a basic level in everyday life, academic and professional They can manage most communication in Mandarin while traveling in China. Achievement Competencies Test participants who are able to pass HSK (Level IV) can communicate in Chinese on various topics and can communicate fluently with native speakers of Mandarin. Achievement Competencies Test participants who can pass HSK (Level V) can read Chinese newspapers and magazines, enjoy Chinese films and drama, and give full speeches in Mandarin. Achievement Competencies Test participants who are able to pass HSK (Level VI) can easily understand written and oral information in Mandarin and can effectively express themselves in Mandarin, both verbally and in writing [1].

The HSK exam is open to the public, and can be taken by anyone who is interested in undergoing the test. Especially considering the importance of HSK certificates in the world of education and employment, as well as increasing public interest in Mandarin. Various schools and universities in East Java include Mandarin as one of the local contents of the institution. besides English and Indonesian. This is certainly very useful for high school or university graduates to add to their soft skills as a provision to find work in the future [4]. Now many multinational companies in Indonesia are in dire need of workers who can speak foreign languages, one of which is Mandarin. In addition to finding employment, HSK certificates are also indispensable for prospective students who wish to continue their studies at universities that use introductory Mandarin courses such as in China, Taiwan and Hong Kong. Some high schools in East Java or universities with mandarin language competency require learners to pass the HSK certification exam at a certain level.

Along with these conditions, many digital technology applications that can be used to assist the learning process of Mandarin, such as Mandarin learning, Chinese Learning Game, Mandarin dictionary, Pleco, and Chinese HSK 1, 2, 3 or 4. The emergence of a blend of innovation products in the field Electronics and Information Technology are driving the development of an HSK application as an assistive medium to support the preparation of the HSK exam [4]. This local application was made in order to complement the media available in the Google Play digital store. Furthermore, this application can be validated in a laboratory environment and simulated to the user directly [5]. This application was tested on SMA Nurul Jadid Probolinggo, as the organizer of the HSK test for students and their target schools. Besides that, it was also applied to students of the Mandarin study program at Widya Kartika University, 
which required their students to pass HSK 5 before graduation. It is expected that this application can be utilized by various groups of students, students or the general public who are interested in preparing for the HSK exam in order to achieve the HSK certificate as needed.

\section{Methodology}

This research is explanatory type research, where in this study tries to explain the relationship between one variable with another. Especially in the ability of technology adaptation of high school/vocational students with college students. This study aims to explain the relationship between variables including ease of use of the value of benefits, satisfaction and motivation towards the use of the HSK exam simulation system in improving the process of understanding in the HSK exam. The type of data in this study is cross-section data where data retrieval is done at a certain time rather than long term (longitudinal) [6].

As subjects in this study are high school/vocational students who have local content in Mandarin, as well as university students majoring in Chinese education who have the obligation to achieve the HSK examination at a certain level. In this study the data analysis was carried out quantitatively based on statistical procedures [7]. In this study, testing and analyzing the influence of exogenous variables, namely the use of applications so as to improve the results of HSK exams on endogenous variables, among others: the value of benefits, ease of use, motivation, as well as being driven by external factors where they must pass the HSK test. The conceptual framework model of this research design can be seen in Figure 1.

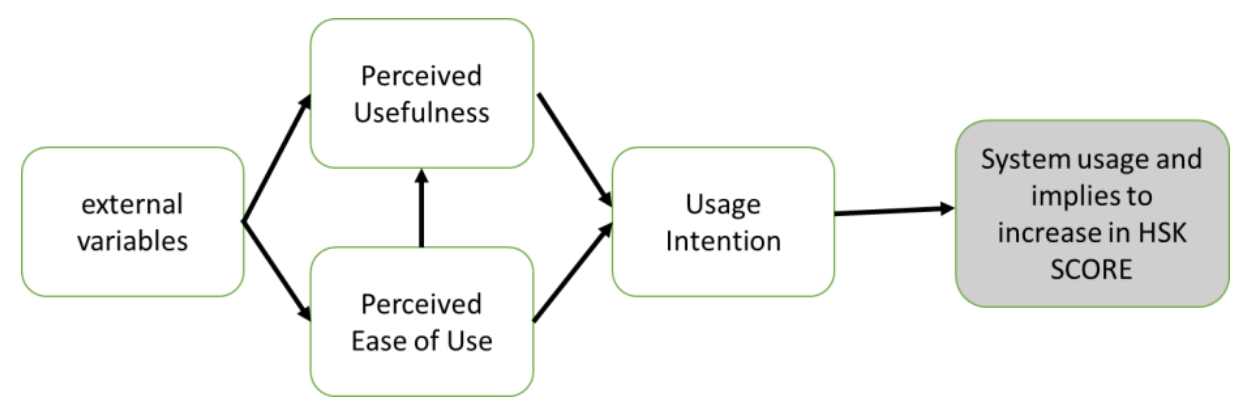

Fig. 1. Conceptual Framework.

\subsection{Samples and Data Collection Techniques}

The sample is part of the population elements to be studied, Acarli [8] states that the sample survey is a procedure where only a portion of the population is taken and used to determine the desired traits and characteristics of the population. The research sample must be able to represent the state of the population, which means the data obtained is sample data. Al-Qaysi [9] said the sample is a portion of the number and characteristics possessed by the population. What is learned from the sample, the conclusion will apply to the population. For that the sample must be truly representative.

There are two things to consider in sampling, namely the number of samples and the sampling technique. Sampling also follows the rules of data from Structural Equation Modeling, namely the number of samples taken ranges from 50-100. with criteria: 
a. The sample of this system is direct users of applications that are high school or vocational students who have Mandarin subjects.

b. The second sample are students from universities majoring in Mandarin education who have the obligation to master HSK at a certain level.

c. The sample uses the HSK exam simulation system as a supporting medium in the learning process.

d. The sample accesses the system more than once and within a predetermined period of time during the system trial.

The sampling technique used in this study is proportional random sampling. Samples were taken based on the population group of students and students, in this case also grouped based on the level of education strata, namely high school/vocational school as the level of basic learning and students as the level of learning in the majors and vocational models.

As a sample of high school students taken from Nurul Jadid Probolinggo High School with a total of 87 respondents and also students majoring in Chinese language education at Widya Kartika University who have tiered from various semesters between semester 2 to the final semester totaling 89 people.

\subsection{Research Instrument}

The research instrument used in this study was a questionnaire and direct observation with a checklist. The questionnaire consisted of a number of structured questions from the indicators of each research variable, which were adopted from various theories and previous studies that were considered to have been tested for their reliability and validity [7].

The list of questions includes student demographic data which includes questions about gender, age, class, length of study of Mandarin, Mandarin language habits, mastery of the amount of vocabulary, experience of participating in the HSK test and the level of user confidence. The next question asks the responses of students who have tried and applied this application, regarding the functionalities of the application. Especially related to the usefulness of the application in helping to prepare users in the face of the HSK exam later. Besides the respondent was asked to provide answers according to the Likert scale, also asked to provide input on the functional application in general whether it can be used as a media to help students in the preparation of the actual HSK exam. The results of the questionnaire from the respondents can be seen in the table About the user's perception of the application used in the trial.

Before the questionnaire is submitted to respondents as many as the number of research samples, it is necessary to test the questionnaire, namely the test of validity and reliability. The aim is to find out whether the questionnaire has the ability to measure what is being measured.

The scale used to measure the latent variables of the study is a Likert scale with a moving interval from range 1 to 5 . In this case the following sequence is made: Strongly agree once given a value of 5, Strongly agree given a value of 4, Agree given a value of 3, Disagree given a value 2, and Strongly disagree with a value 1 . Likert scale is suitable to be used to measure respondents' attitudes and perceptions on the statements listed in the questionnaire [4].

\subsection{Validity and Reliability Test}

Validity means the extent to which the accuracy and accuracy of a measuring instrument in carrying out its measurement function. Dikko [5] states that the validity test is used to measure whether or not an indicator is valid or valid. An indicator is valid if the indicator is able to express something that will be measured by the board. The indicator is said to have good validity 
to a latent structure if the standardized factor loading is greater than or equal to 0.5 , the critical ratio value on the standardized factor loading is greater than the critical value of 1.96 .

The reliability test aims to determine the consistency and stability of a score (measurement scale). Hari [10] states that reliability is a tool to measure the reliability or consistency of an indicator in a construct. A construct is said to be reliable or reliable if one's response to a statement is consistent or stable from time to time. The reliability test calculation process can be used as follows:

$$
\frac{\left(\sum_{i=1}^{p} \lambda_{i}\right)^{2}}{\left(\sum_{i=1}^{p} \lambda_{i}\right)^{2}+\sum_{i}^{p} \mathrm{~V}(\delta)}
$$

Where:

$$
\begin{array}{ll}
\lambda_{\mathrm{i}} & =\text { completely standardized loading for the } i \text { th indicator } \\
\mathrm{V}\left(\delta_{\mathrm{i}}\right) & =\text { variance of the error term for the } i \text { th indicator } \\
\mathrm{p} & =\text { number of indicators }
\end{array}
$$

The output from calculations using SPPS for the data can be seen on table 1 as follows.

Table 1. Item-Total Statistics

\begin{tabular}{ccccc}
\hline & $\begin{array}{c}\text { Scale Mean if } \\
\text { Item Deleted }\end{array}$ & $\begin{array}{c}\text { Scale Variance if } \\
\text { Item Deleted }\end{array}$ & $\begin{array}{c}\text { Corrected Item- } \\
\text { Total Correlation }\end{array}$ & $\begin{array}{c}\text { Cronbach's Alpha } \\
\text { if Item Deleted }\end{array}$ \\
\hline X1 & 31,6197 & 102,582 &, 753 &, 954 \\
X2 & 31,1127 & 99,101 &, 826 &, 952 \\
X3 & 31,1408 & 98,551 &, 844 &, 951 \\
X4 & 30,8873 & 98,616 &, 771 &, 954 \\
X5 & 30,9014 & 97,662 &, 795 &, 953 \\
X6 & 31,2394 & 98,470 &, 795 &, 953 \\
X7 & 31,0000 & 97,600 &, 776 &, 954 \\
X8 & 30,9014 & 98,776 &, 801 &, 952 \\
X9 & 30,7324 & 96,742 &, 896 &, 949 \\
X10 & 30,6479 & 97,374 &, 857 &, 950 \\
\hline
\end{tabular}

\section{Findings and Discussion}

Based on the results of the research that has been done, several results can be collected as follows:

A very strong correlation between external factors is the value of the HSK exam as a prerequisite for graduation from a Mandarin language education program at a certain level. This makes it a motivation for users to try the HSK simulation exam application system. Gradually users of this system must find the value of ease in the system first, if they are able to use this system well will gradually also move on to increase their understanding whether the system is 
able to be useful to them. If the user is unable to find the value of the benefits of the system will certainly cause a negative value of intention to use from the user of the system.

On the other hand, an increase in the value of the perceive ease of use or ease of use of the system is able to cause users to try this system and after being tested for a while they will start to get used to using the existing system. So, they can feel the value of the benefits of the existing system. Furthermore, it will motivate users to continue to use this system so as to be able to improve the ability of learners, especially in increasing the HSK exam scores they take. From the value of learners between high school and students have different values in understanding or the results of trials that have been done. This shows a fundamental difference in motivation between the material mastery needs of high school students towards students.

\subsection{System Implementation}

The technological tools generated from this research are web-based HSK exam simulation applications. This application can be accessed through the website address http://uwikamandarin.com. The main menu of this application can be seen in Figure 1. To enter this application, the user must log in with the appropriate username and password. This access right is obtained through the registration process first from the signup module. User activities as test participants, in addition to seeing the material provided in the material module or trying to simulate the HSK exam. The exam material provided includes vocabulary for each level, as well as Mandarin reading, listening and writing material. Each Mandarin vocabulary is displayed in pinyin \& hanzi letters, and is equipped with meanings, levels, categories in Indonesian and how to read them.

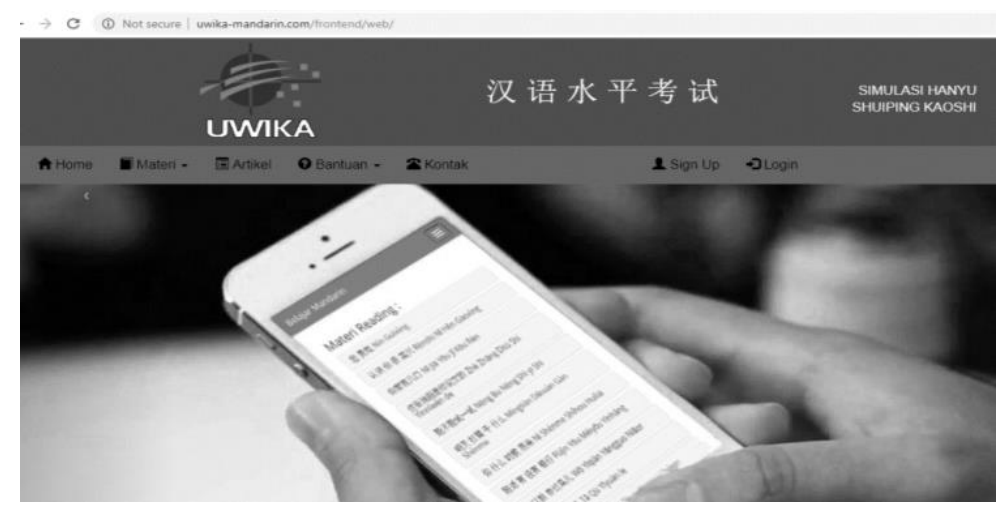

Fig. 2. HSK Simulation Application.

Besides searching the exam material that can be learned at any time, the user can simulate HSK exams according to the chosen level. The user can access the simulation module and select the desired exam questions by pressing the button available according to the level of the mock HSK exam desired, as well as the HSK 5 exam questions as shown in Figure 2. The user can complete the simulation test until the time limit has been provided by the application and can see the simulation results and print them as needed. 


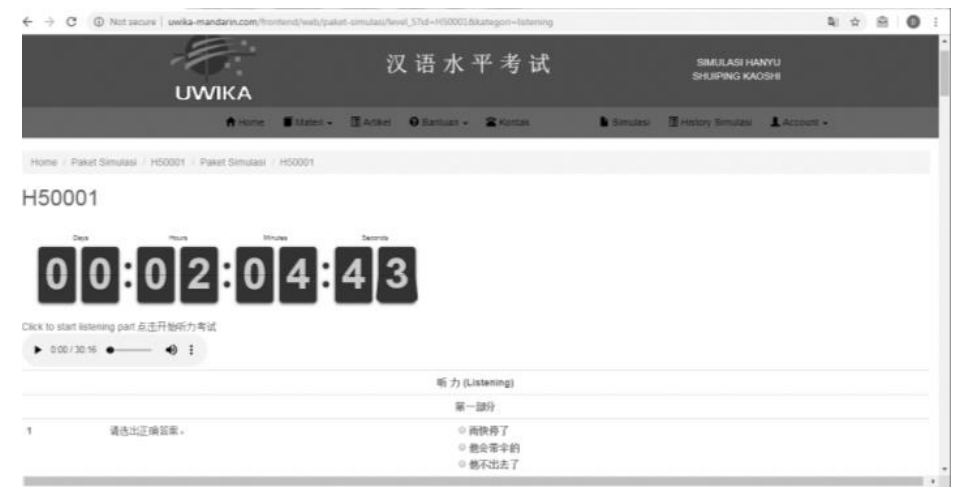

Fig. 3. HSK Simulation Test Interface.

This application was tested on high school students Nurul Jadid Probolinggo East Java, which was followed by 87 students. Basically, they are familiar with the forms of online HSK exam application provided by various sources from the Internet, such as from the website www.chinesetest.cn, ewww.hskonline.com and https://mandarinbean.com. Even before the HSK exam, they usually follow the guidance in schools for HSK exam simulation from Hanpan in Mandarin. While those used in the HSK exam simulation application use more explanation in Indonesian. This application has also previously been used by students of educational and Mandarin courses and students who have taken Mandarin certification. Aside from ordinary users, this application is managed by an admin and several contributors. A contributor thinks to manage simulation exam questions and question banks, as well as provide evaluations. While an application administrator plays an important role in the application. Besides acting as a contributor, it also manages other users, learning themes, content carousels, FAQs, articles and reports on the results of HSK exam simulation. Based on the results of application trials implemented by high school and university students, feedback was obtained regarding the performance of the application. Reward is given in the form of a questionnaire distributed to application users.

Table 2. User Perception of the Application

\begin{tabular}{|c|c|c|c|c|}
\hline \multirow[t]{2}{*}{ Question } & \multicolumn{2}{|c|}{$\begin{array}{l}\text { Questionnaire High } \\
\text { School student }\end{array}$} & \multicolumn{2}{|c|}{$\begin{array}{l}\text { Questionnaire } \\
\text { undergraduate }\end{array}$} \\
\hline & Mean (\%) & Mean $(\%)$ & Mean $(\%)$ & Mean $(\%)$ \\
\hline $\begin{array}{l}\text { Ease the process of registering and } \\
\text { editing profiles }\end{array}$ & $\begin{array}{c}3,01 \\
(60,28)\end{array}$ & & $\begin{array}{c}3,58 \\
(71,67)\end{array}$ & \\
\hline $\begin{array}{l}\text { The features of the application are } \\
\text { easy to understand and user } \\
\text { friendly }\end{array}$ & $\begin{array}{c}3,52 \\
(70,42)\end{array}$ & & $3,5(70,00)$ & \\
\hline $\begin{array}{l}\text { Ease of user accessing the } \\
\text { available modules }\end{array}$ & $\begin{array}{c}3,54 \\
(70,70)\end{array}$ & & $\begin{array}{c}3,83 \\
(76,67)\end{array}$ & \\
\hline $\begin{array}{l}\text { The exam material is in } \\
\text { accordance with the requirements } \\
\text { of the HSK exam }\end{array}$ & $\begin{array}{c}3,79 \\
(75,77)\end{array}$ & & $\begin{array}{c}4,00 \\
(80,00)\end{array}$ & \\
\hline $\begin{array}{l}\text { The exam simulation supports the } \\
\text { actual HSK exam }\end{array}$ & $\begin{array}{c}3,77 \\
(75,49)\end{array}$ & & $\begin{array}{c}3,75 \\
(75,00)\end{array}$ & \\
\hline
\end{tabular}




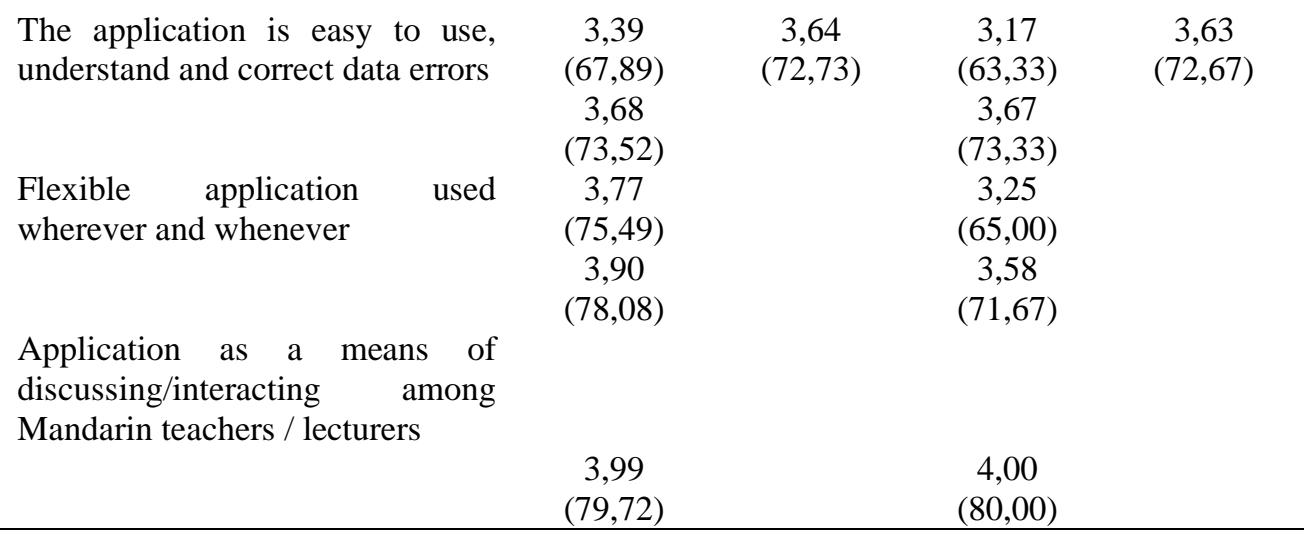

Based on the results of the questionnaire, high school students stated that the content was easy to understand, seen from the appearance $(70.42 \%)$, the material $(75.77 \%)$, and the simulation exam to support the HSK exam (75.49\%). Likewise, from the operational side, that the module is easily accessible, $(70.70 \%)$, interactive $(75.49 \%)$, flexible $(73.52 \%)$ and the simulation results are easily understood $(78.08 \%)$. The respondents also stated that the higher the frequency of application utilization, the more effective and added user confidence to pass the HSK exam. Overall that the application can be used as a supporting medium for preparation of HSK exam preparation. The statement of Nurul Jadid High School students did not differ greatly from the respondents of Mandrin Language and Education Study Program students or UWIKA Mandarin language certification students. They stated that the application significantly (72.67\%) could be accepted as an assistive medium for the preparation of the HSK exam [2].

\section{Conclusion}

HSK certification shows valid recognition of one's Mandarin language skills. A person who has an HSK certificate, has the opportunity to enter the workforce in both the local and global markets. Likewise, this certificate is required for prospective students as entry requirements for higher education or for achieving scholarship students from various universities that use Mandarin as the language of instruction, such as in China, Taiwan or Hong Kong. for non-native speakers, must pass the HSK test Obtain HSK certificate documents, for non-native speakers through the results of passing the HSK exam. Efforts to help someone prepare for the HSK exam, including making it a habit to practice HSK exams through online mock exams. From this research an online HSK exam simulation application has been produced that supports this goal. The application has been tested on high school and Mandarin students who must have a HSK certificate at a certain level before graduating. Based on the results of the questionnaire from the application's users, on average they stated that the application could be used as a significant supporting medium (3.63 from Sections 1-5) for the actual preparation of the HSK exam. 


\section{Acknowledgements}

Acknowledgments were given to the LPPM of Universitas Widya Kartika and the Ministry of Research, Technology and Higher Education Ministry of Research and Technology Ministry for funding this research through the applied research grant scheme.

\section{References}

[1] Y. Teng, "Hanyu Shuiping Kaoshi (HSK): Past, present, and future," in Chinese as a second language assessment, Springer, 2017, pp. 3-19.

[2] D. Darmanto, Y. Hari, B. Hermawan, and E. Setyawati, "Aplikasi Sistem Manajemen Konten Bahasa Mandarin untuk Mendukung Ujian Hanyu Shuiping Kaoshi," J. Teknol. Inf. dan Ilmu Komput., vol. 6, no. 1, pp. 9-16, 2019 .

[3] M. Tseng, C.-H. Lin, and H. Chen, "An immersive flipped classroom for learning Mandarin Chinese: Design, implementation, and outcomes," Comput. Assist. Lang. Learn., vol. 31, no. 7, pp. 714-733, 2018.

[4] D. Darmanto, Y. Hari, and B. Hermawan, "Mobile learning application to support Mandarin language learning for high school student," Imp. J. Interdiscip. Res., vol. 2, no. 4, pp. 402-407, 2016.

[5] M. Dikko, "Establishing Construct Validity and Reliability: Pilot Testing of a Qualitative Interview for Research in Takaful (Islamic Insurance).," Qual. Rep., vol. 21, no. 3, 2016.

[6] Y. Hari and B. Hermawan, "Rancang Bangun Media Pembelajaran Bahasa Mandarin Berbasis Mobile Learning," J. Nas. Pendidik. Tek. Inform. JANAPATI, vol. 4, no. 1, pp. 1-6, 2015.

[7] Y. Hari, D. Aspali, and B. Hermawan, "Interpretasi e-learning sebagai support media untuk pembelajaran Bahasa Mandarin bagi siswa sekolah dasar," J. Inform., vol. 12, no. 2, pp. 77-83, 2014.

[8] D. S. Acarli and Y. Sağlam, "Investigation of pre-service teachers' intentions to use of social media in teaching activities within the framework of technology acceptance model," ProcediaSocial Behav. Sci., vol. 176, pp. 709-713, 2015.

[9] N. Al-Qaysi, N. Mohamad-Nordin, and M. Al-Emran, "A systematic review of social media acceptance from the perspective of educational and information systems theories and models," $J$. Educ. Comput. Res., vol. 57, no. 8, pp. 2085-2109, 2020.

[10] Y. Hari and L. P. Dewi, "Forecasting system approach for stock trading with relative strength index and moving average indicator.” Petra Christian University, 2018. 